\title{
MORPHOLOGICAL AND MOLECULAR CHARACTERIZATION OF RHIZOCTONIA Oryzae sativae IN BANGLADESH
}

\author{
S.B. Jahan ${ }^{1}$, M.A. Ali ${ }^{2}$, M.S. Alam ${ }^{3}$,Z.R. Moni ${ }^{4 *}$ and M.A. Latif \\ ${ }^{1}$ Govt. Teacher's Training College, Mymensingh, Bangladesh \\ ${ }^{2}$ Bangladesh Rice Research Institute, Joydebpur, Gazipur-1701, Bangladesh \\ ${ }^{3}$ Department of Botany, Rajshahi University, Bangladesh \\ ${ }^{4}$ Bangladesh Agricultural Research Council, Dhaka, Bangladesh \\ ${ }^{5}$ Plant Pathology division, Bangladesh Rice Research Institute, Joydebpur, Gazipur, Bangladesh
}

\begin{abstract}
Aggregate sheath spot disease of rice caused by Rhizoctonia oryzaesativae has emerged in higher incidence in North-Western region of Bangladesh. Thirty isolates of $R$. oryzae-sativae were studied by using morphological and molecular marker. Isolates were confirmed using specific primer where a single band of $1200 \mathrm{bp}$ was amplified. Two distinct groups relatively slow and faster were found in mycelal growth. Molecular characterization was done using four primers and DNA band ranged from 0.25 to $2.21 \mathrm{~kb}$. A combined dendrogram was constructed which separated the isolates into three groups at $69.6 \%$ similarity level. All isolates placed in two major clusters except isolate RA-1 placed in cluster group III but were not grouped according to their geographic origins. Fast growing isolates have been placed in Group II while slow growing isolates in cluster group I. The similarity coefficient values of the dendrogram profile ranged from 0.36 to 0.98 with an average of 0.67. Diversity of different isolate showed that significant variation was present among the isolate and were not genetically identical.
\end{abstract}

Keywords: Aggregate sheath spot Rhizoctonia oryzae-sativae; variable number tandem repeat (VNTR); repetitive-element polymerase chain reaction (Rep-PCR)

\section{INTRODUCTION}

Sheath diseases of rice are the major constraints of rice production in Bangladesh. Among them Rhizoctonia sheath diseases of rice are predominant comprise of sheath blight, sheath spot and aggregate sheath spot. Significant yield losses in rice growing regions of the world have been reported by (Kobayashi et al., 1997 and Johanson et al., 1998). The emergence of Rhizoctonia sheath diseases as economically important

\footnotetext{
* Corresponding author email: zrmoni@yahoo.com
} 
rice diseases in recent that attributed to the intensifications of rice-cropping; development of high-yielding rice cultivar with dwarf plant type, high-tillering along with high plant densities. In contrast, only a few studies have been concerned with Rhizoctonia oryzae-sativae in Bangladesh. Aggregate sheath spot of rice caused by Rhizoctonia oryzae-sativae, occurs in Bangladesh and in other countries including United states (Gunnel et al., 1984), Japan, Vietnam, India, Thailand, Iran, Venezuela, Uruguay and Australia (Cedeno et al., 1998, Rahimian et al.,1989, Gunnel et al., 1992, Lanoiselet et al., 2007). Rhizoctonia oryzae-sativae belongs to the AG-Bb anastomosis group of binucleate Rhizoctonia spp. (Gunnel et al., 1992). Rhizoctonia oryzae-sativae has been distinguished from other Rhizoctonia spp. by amplified fragment length polymorphism (Taheri et al., 2007) specific primers (Johanson et al., 1998) and fatty acid analysis (Lanoiselet et al., 2005). However, intraspecific genetic diversity of Rhizoctonia oryzae-sativae had examined by only a few workers in the world (Chaizuckam and Davis, 2010). Somatic incompatibility has been used as a marker to identify isolates of Rhizoctonia oryzae-sativae in order to determine the survival of overwintering inoculum and dissemination of the fungus in rice field in Japan (Guo et al., 2006). Isolates that have somatic incompatibility reactions produced growth inhibition zones or barrage zones due to plasmolysis of fused cells; this reaction occurs between genetically distinct isolates, whereas a compatible reaction produces confluent growth and living fusion of cytoplasm between isolates (Sneh et al., 1991). Compatible reactions usually observed in self pairing and may indicate that the isolates are genetically similar. Somatic compatibility was tested to characterize Rhizoctonia oryzae-sativae. The powerful tools have been used in genetic analysis of numerous organisms, including animals, plants, gene flow, intraspecific phylogeny, mating systems and gene mapping (Barroso et al., 2000, Douhan et al., 2003). Since breeding for disease resistance has become an important program taken up by many workers, an attempt was made in this study to differentiate the pathogen of the isolates and establish the type of resistance in term of vertical or horizontal, as defined, and offered by the rice cultivars against the pathogen studies at the DNA level have also advanced our understanding of the structure of Rhizoctonia populations (Vandermark., 1999). Molecular tools are being increasingly used to characterize fungal plant pathogen and to evaluate level of genetic diversity within and between species and to identify particular pathotype. Scientific information on aggregate sheath spot of rice is scanty in Bangladesh and the population diversity need to be studied. However, knowledge of the population of pathogenic Rhizoctonia oryzae-sativae is essential for integrated control strategies; along with the understanding of the influence of other characteristics, including virulence, host range and adaptability to environmental conditions. Perhaps this is the first comprehensive report in which thirty isolates of $R$. oryzae-sativae collected from rice fields in Bangladesh. Worldwide, aggregate sheath spot and sheath spot have received little attention compared with the disease sheath blight, caused by Rhizoctonia solani. However, aggregate sheath spot is clearly becoming increasingly 
important in temperate rice-growing regions. Furthermore, the recent report of the potential yield losses caused by both diseases has demonstrated the potential threat both diseases represent to temperate rice industries. Multi-disciplinary approaches using diagnostics techniques were undertaken to characterize of morphological and genetic variability among the collected isolates of Rhizoctonia oryzae-sativae isolates of different locations of Bangladesh.

\section{MATERIALS AND METHODS}

\section{Collection, purification and identification of $R$. oryzae-sativae}

A total of 30 isolates of $R$. oryzae-sativae were isolated from rice sheaths with aggregate sheath spot symptoms in disease prone area of Bangladesh (Table 1). Single hyphal tip method was followed for isolation and purification was confirmed by constricted hyphae and bi-nucleate cells (Mordue., 1974). All isolates was also confirmed by molecular identification (Johanson et al., 1998). DNA was extracted from 30 isolates of $R$. oryzae-sativae following the methods of (Raeder and Broda., 1985). For direct detection and identification of $R$. oryzae- sativae, PCR was performed using $R$. oryzae-sativae specific primers on 30 isolates. The PCR was conducted with the combination of forward Primer GMROS-6 (5'-GAA AGA GAG AGA GGT CGC CTC-3') and reverse primer R635 (5'-GGT CCG TGT TTC AAG ACG G-3'). PCR amplification was used to complete the reaction. Aliquots (10 $\mu 1$ of the amplification products) were subjected to electrophoresis using $2 \%$ agarose gel with TBE buffer at $100 \mathrm{~V}$ for 1:20 min, stained with ethidium bromide and visualized using a UV trans-illuminator.

\section{Cultural and morphological characterization}

Mycelial disks of $6 \mathrm{~mm}$ diameter of 3 days old colonies were transferred aseptically to PDA plates for 2 weeks with three replications. Qualitative cultural characteristics viz., Sclerotial size placing the sclerotia were examined. Data were analyzed using MSTATC (version 2.10), in a two-way Analysis of Variance (ANOVA) of 30 treatments. Mean separation was performed using least significant difference (LSD) test at $\alpha=0.05$.

\section{Somatic compatibility test}

Mycelial plugs having $6 \mathrm{~mm}$ diameter from 3 days old culture and placed on $9 \mathrm{~cm}$ diameter petri plates were approximately $2 \mathrm{~cm}$ apart from each other. Three isolates per plate were placed and preserved for 10 days. Isolates failed to show a barrage reaction at the colony junction were classified as same somatic compatibility groups (SCGs), while isolates exhibiting a barrage reaction were classified into different SCGs. Thirty isolates were tested in all possible combination with three replications.

\section{Molecular characterization}

For molecular characterization three primers, MR (GAG GGT GGC GGT TCT), RY (CAG CAG CAG CAG CAG) and GF (TCC TCC TCC TCC TCC) were used for 
VNTR analysis. BOXA1R primer (5'-CTACGGCAAGGCGACGCTGACG-3') used for REP-PCR analysis. Genotypic data were obtained by considering different product sizes as different alleles at each locus, which were measured by AlphaEase FC 4.0 software and then scored for the presence (1) or absence (0) of the bands at the certain position for each isolate. A similarity matrix based on Dice's similarity coefficient was used and cluster analysis of the matrix was done using unweighted pair group method with arithmetic mean (UPGMA) by numerical taxonomy and multivariate analysis system (NTSYS-PC) version 2.20e. Under SIMQUAL program similarity matrix was constructed using Dice coefficient method.

\section{RESULTS}

\section{Identification of isolates, cultural and morphological characterization, SCGs test.}

All isolates identified as $R$. oryzae-sativae by the presence of constricted hyphae and binucleate cells (Table 1) and using specific primers. A single band of 1200 bp was amplified using forward primer GMROS-6 with the combination of reverse primer R635 (Fig. 2).

Morphological studies showed variability in colonies among the isolates on PDA were white initially but turned to pale brown later. Abundant aerial mycelium were produced by JA-1 and JA-3 while the others produced a few or moderate quantity of aerial mycelium. All isolates produced sclerotia in culture and their colors were varied from light brown, brown to dark brown. Mean sclerotial size varied from $0.56 \mathrm{~mm}$ (small; $0.5 \mathrm{~mm}-<1 \mathrm{~mm}$ ) to $1.99 \mathrm{~mm}$ (large $1 \mathrm{~mm}-2 \mathrm{~mm}$ ). All isolates produced superficial sclerotia except TA-1, TA-3, MY-1, MY-2, MY-3, JA-2, SH-3, NA-1, NA-2. These isolates produced sclerotia both on mycelia and embedded in agar. Some isolates scattered all over the plate, while some were aggregated only at the center. The growth rate of isolates measured between $6.10-10.90 \mathrm{~mm}$ per day in which maximum and minimum growths were observed in MY-1 and NE-2 respectively (Table 1). Accordingly, the studied isolates by least significant difference test indicated that there was a significant difference $(\alpha=0.050)$ within fungal isolates growth rates in which isolates were categorized into two distinct groups indicating low (DI-1, DI-2, DI-3, TH-1, TH-2, TH-3, RA-1, RA-2, RA-3, NE-1, NE-2, Ne-3, GA-1, GA-2, GA-3 ) and high (MY-1, MY-2, MY-3, TA-1, TA2, TA-3, JA-1, JA-2, JA-3, SH-1, SH-2, SH-3, NA-1, NA-2, and NA-3) growth rate.

\section{Somatic compatibility test}

Only three pairs of isolates displayed somatic compatible reactions; one pairs from Tangail district (TA-1+ TA-3), one from Gazipur (GA-2+GA-3) districts and one pair between Mymensingh (MY-1+SH-3) and Sherpur districts. There were 27 SCGs from 30 isolates indicated $90 \%$ diversity among the isolates. 
Table 1. Source of isolates of R.oryzae-sativae and their cultural characteristics

\begin{tabular}{|c|c|c|c|c|c|c|c|c|}
\hline \multirow[t]{2}{*}{ Isolates } & \multirow[t]{2}{*}{ Origin } & \multirow{2}{*}{$\begin{array}{c}\text { Agroecologica } \\
1 \text { zone(AEZ) }\end{array}$} & \multirow{2}{*}{$\begin{array}{c}\text { Longitude } \\
\text { and } \\
\text { Latitude } \\
\left({ }^{0}\right)\end{array}$} & \multirow{2}{*}{$\begin{array}{l}\text { Growth rate } \\
(\mathrm{mm} / \mathrm{day})^{\mathrm{a}}\end{array}$} & \multicolumn{2}{|c|}{ 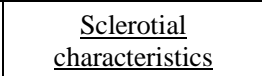 } & \multicolumn{2}{|c|}{ Virulence test } \\
\hline & & & & & Inten & $\begin{array}{l}\text { bize } \\
\text { size }^{c} \text { Mean }\end{array}$ & \multicolumn{2}{|c|}{$\begin{array}{l}\mathrm{RLH}(\mathrm{cm})^{\mathrm{d}} \text { Incidence } \\
(\%)^{\mathrm{e}}\end{array}$} \\
\hline DI-1 & \multirow[t]{3}{*}{ Dinajpur } & \multirow[t]{3}{*}{01} & \multirow{3}{*}{$\begin{array}{l}88.63 \mathrm{E} \\
25.62 \mathrm{~N}\end{array}$} & $7.20 \mathrm{HI}$ & + & 0.72 & $6.97 \mathrm{LM}$ & $44.19 \mathrm{~N}$ \\
\hline DI-2 & & & & $7.33 \mathrm{H}$ & + & 0.56 & $9.44 \mathrm{GHI}$ & $48.78 \mathrm{KLM}$ \\
\hline DI-3 & & & & $7.17 \mathrm{HIJ}$ & + & 0.61 & $7.85 \mathrm{IJKL}$ & $45.83 \mathrm{MN}$ \\
\hline TH-1 & \multirow[t]{3}{*}{ Thakurgaon } & \multirow[t]{3}{*}{01} & $88.45 \mathrm{E}$ & $6.80 \mathrm{IJKL}$ & + & 0.92 & $8.07 \mathrm{JKL}$ & $45.65 \mathrm{MN}$ \\
\hline TH-2 & & & $26.02 \mathrm{~N}$ & $6.43 \mathrm{LM}$ & + & 0.85 & $6.58 \mathrm{M}$ & $47.83 \mathrm{LMN}$ \\
\hline TH-3 & & & & $6.57 \mathrm{KLM}$ & + & 0.77 & $7.03 \mathrm{LM}$ & $51.85 \mathrm{HIJK}$ \\
\hline RA-1 & \multirow[t]{3}{*}{ Rajshahi } & \multirow[t]{3}{*}{11} & $88.06 \mathrm{E}$ & 6.90 HIJKL & + & 0.90 & $8.41 \mathrm{IJK}$ & 52.94 GHIJ \\
\hline RA-2 & & & $24.36 \mathrm{~N}$ & $7.00 \mathrm{HIJK}$ & + & 0.69 & $7.83 \mathrm{JKLM}$ & $57.45 \mathrm{~F}$ \\
\hline RA-3 & & & & $7.10 \mathrm{HIJ}$ & + & 0.75 & $8.34 \mathrm{IJK}$ & $51.16 \mathrm{IJKL}$ \\
\hline My-1 & \multirow{3}{*}{$\begin{array}{l}\text { Mymensing } \\
\mathrm{h}\end{array}$} & \multirow{3}{*}{09} & $90.40 \mathrm{E}$ & $10.90 \mathrm{~A}$ & +++ & 1.52 & $14.90 \mathrm{~B}$ & $56.52 \mathrm{FG}$ \\
\hline MY-2 & & & $24.74 \mathrm{~N}$ & $10.20 \mathrm{BC}$ & ++ & 1.79 & $14.38 \mathrm{BC}$ & $62.26 \mathrm{BCDE}$ \\
\hline MY-3 & & & & $10.33 \mathrm{~B}$ & +++ & 1.81 & $18.62 \mathrm{~A}$ & $58.54 \mathrm{DEF}$ \\
\hline GA-1 & \multirow[t]{3}{*}{ Gazipur } & \multirow[t]{3}{*}{28} & $90.41 \mathrm{E}$ & $7.20 \mathrm{HI}$ & + & 0.68 & $7.89 \mathrm{JKL}$ & $65.58 \mathrm{~B}$ \\
\hline GA-2 & & & $23.99 \mathrm{~N}$ & 7.67 HIJK & + & 0.82 & 8.95 HIJ & $62.96 \mathrm{BC}$ \\
\hline GA-3 & & & & $6.80 \mathrm{IJKL}$ & + & 0.75 & $8.28 \mathrm{IJKL}$ & $59.09 \mathrm{CDEF}$ \\
\hline TA-1 & \multirow[t]{3}{*}{ Tangail } & \multirow[t]{3}{*}{09} & $89.92 \mathrm{E}$ & $9.20 \mathrm{FG}$ & +++ & 1.95 & $11.77 \mathrm{EF}$ & $69.90 \mathrm{~A}$ \\
\hline TA-2 & & & $24.42 \mathrm{~N}$ & $9.43 \mathrm{EFG}$ & +++ & 1.25 & $8.75 \mathrm{IJK}$ & $57.78 \mathrm{~F}$ \\
\hline TA-3 & & & & 9.67 DEF & +++ & 1.68 & $12.21 \mathrm{E}$ & $58.70 \mathrm{DEF}$ \\
\hline NE-1 & \multirow[t]{3}{*}{ Netrokona } & \multirow[t]{3}{*}{09} & $90.82 \mathrm{E}$ & $6.57 \mathrm{KLM}$ & + & 0.75 & $8.21 \mathrm{IJKL}$ & $52.83 \mathrm{GHIJ}$ \\
\hline NE-2 & & & $24.88 \mathrm{~N}$ & $6.10 \mathrm{M}$ & + & 0.68 & 7.79 JKLM & 49.06 JKLM \\
\hline NE-3 & & & & $6.67 \mathrm{JKL}$ & + & 0.60 & 7.47 KLM & $48.21 \mathrm{KLM}$ \\
\hline JA-1 & \multirow[t]{3}{*}{ Jamalpur } & \multirow[t]{3}{*}{09} & $89.94 \mathrm{E}$ & $9.63 \mathrm{DEF}$ & ++ & 1.99 & $10.57 \mathrm{FG}$ & $57.50 \mathrm{~F}$ \\
\hline JA-2 & & & $24.92 \mathrm{~N}$ & $9.80 \mathrm{CDE}$ & +++ & 1.89 & $12.75 \mathrm{DE}$ & $58.33 \mathrm{EF}$ \\
\hline JA-3 & & & & 9.53 DEFG & +++ & 1.73 & $14.26 \mathrm{BC}$ & $62.50 \mathrm{BCD}$ \\
\hline SH-1 & \multirow[t]{3}{*}{ Sherpur } & \multirow[t]{3}{*}{09} & $90.01 \mathrm{E}$ & 9.90 BCDE & +++ & 1.81 & $9.41 \mathrm{GHI}$ & $58.93 \mathrm{DEF}$ \\
\hline $\mathrm{SH}-2$ & & & $25.01 \mathrm{~N}$ & $10.00 \mathrm{BCD}$ & ++ & 1.35 & $14.30 \mathrm{BC}$ & $62.50 \mathrm{BCD}$ \\
\hline SH-3 & & & & $10.03 \mathrm{~B}$ & ++ & 1.58 & $10.26 \mathrm{GH}$ & $53.33 \mathrm{GHI}$ \\
\hline NA-1 & \multirow[t]{3}{*}{ Narsingdi } & \multirow[t]{3}{*}{09} & $90.79 \mathrm{E}$ & 9.50 DEFG & +++ & 1.45 & $13.52 \mathrm{CD}$ & $50.98 \mathrm{IJKL}$ \\
\hline NA-2 & & & $23.99 \mathrm{~N}$ & $9.10 \mathrm{G}$ & ++ & 1.64 & $15.07 \mathrm{~B}$ & $65.22 \mathrm{~B}$ \\
\hline NA-3 & & & & $9.73 \mathrm{CDE}$ & +++ & 1.73 & $12.61 \mathrm{DE}$ & $55.56 \mathrm{FGH}$ \\
\hline
\end{tabular}

${ }^{a}$ Colony diameter after 3 days on PDA.Values in growth rate columns followed by the same letter are not significantly different at $\alpha=0.05$ after ANOVA-LSD test

bintensity : + slight; ++ moderate; +++ profuse

size: in $\mathrm{mm}$; small $(0.5 \mathrm{~mm}-<1 \mathrm{~mm})$; large $(1 \mathrm{~mm}-2 \mathrm{~mm})$

${ }^{\mathrm{d}}$ Values in RLH columns followed by the same letter are not significantly different at $\alpha=0.05$ after ANOVA-LSD test

${ }^{\mathrm{e}}$ Values in incidence columns followed by the same letter are not significantly different at $\alpha=0.05$ after ANOVALSD test 


\section{DNA fingerprint analysis}

Genetic variation was determined among $30 \mathrm{R}$. oryzae-sativae isolates using VNTR (MR, GF, RY) and BOXA1R primers. All the primers amplified reproducible bands and its bands' sizes ranged from 0.26 to $2.21 \mathrm{~kb}$ for VNTR primers and 0.25 to 2.02 $\mathrm{kb}$ for BOXA1R primer. The maximum and minimum number of bands was obtained from GF and RY respectively. VNTR primers amplified 30 bands from which GF showed the highest polymorphism (100\%) and the lowest polymorphism showed by RY $(75 \%)$. Out of 11 bands 1 was monomorphic resulting 90\% polymorphism by BOXA1R primer. From all the 41 distinct and clear bands were scored of which only 4 bands were shared by all and 37 bands were polymorphic resulting $90 \%$ of scored bands being polymorphic. The gel picture of GF primer is presented in Fig. 3.

\section{Cluster analysis}

Application of the UPGMA clustering method gave the cophenetic correlation coefficient, where $r=0.82$ indicates a good fit correlation value. The similarity coefficient values varied from 0.36 to 0.98 with an average of 0.67 , indicating variation among the isolates. 29 isolates grouped into 2 clusters at $69.6 \%$ similarity level. Cluster I composed of 14 isolates. This cluster consists of all comparatively slow growing isolates. Cluster II composed of 15 isolates and consisted of all comparatively fast growing isolates. One separate solitary group resulted from the VNTR and REP-PCR marker data for RA-1 which comprised Cluster III (Fig. 4). The highest genetic similarity was found between MY-1 and SH-3 (98\%) followed by TA-1 and TA-3 (97\%) while lowest genetic similarity shared between RA-1 and SH$1(36 \%)$ followed by RA-1 and JA-1(38\%).

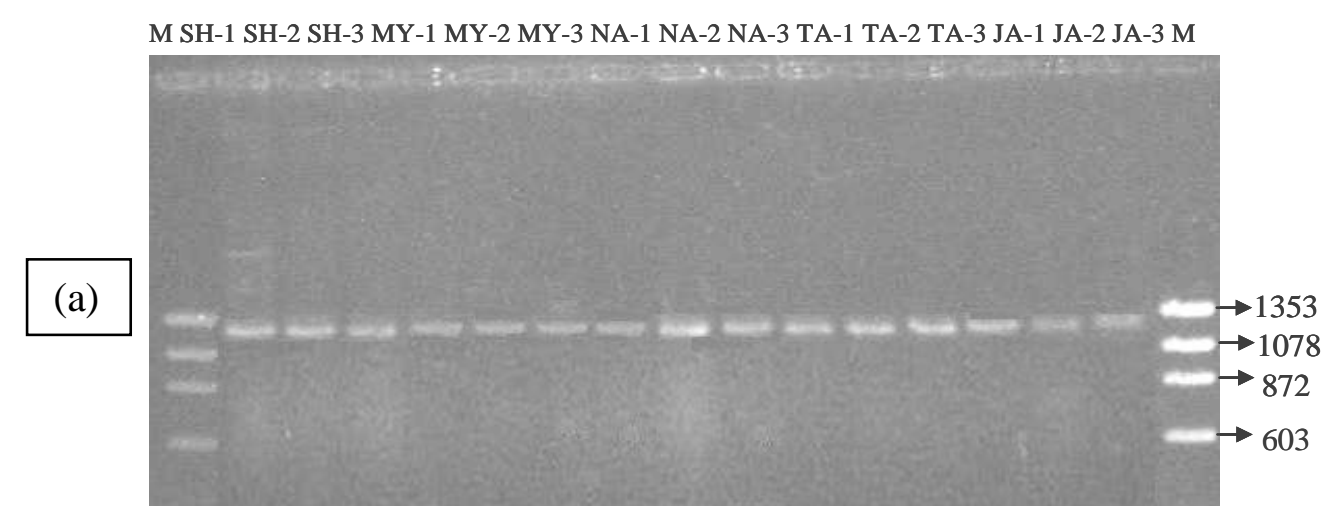

Figure 1. PCR amplification of total genomic DNA from 15 isolates of R.oryzaesativae, using specific primer. 
(b)

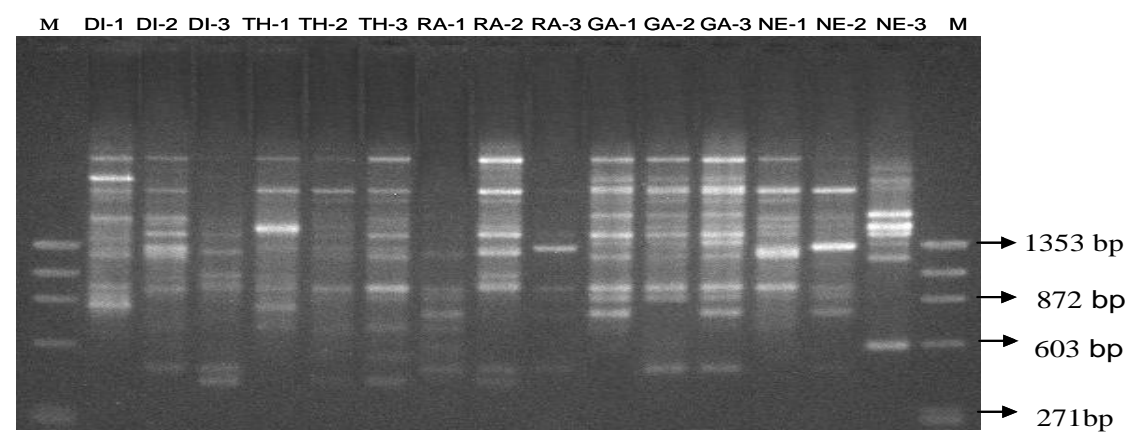

Fig.2. PCR amplification of total genomic DNA from 15 isolates (SH-1-JA-3) of R.oryzaesativae using the primer pairs of GMROS-6 with R635: Lanes: M, PhiX174/HaeIII markers (Promega) (one gel picture shown in here)

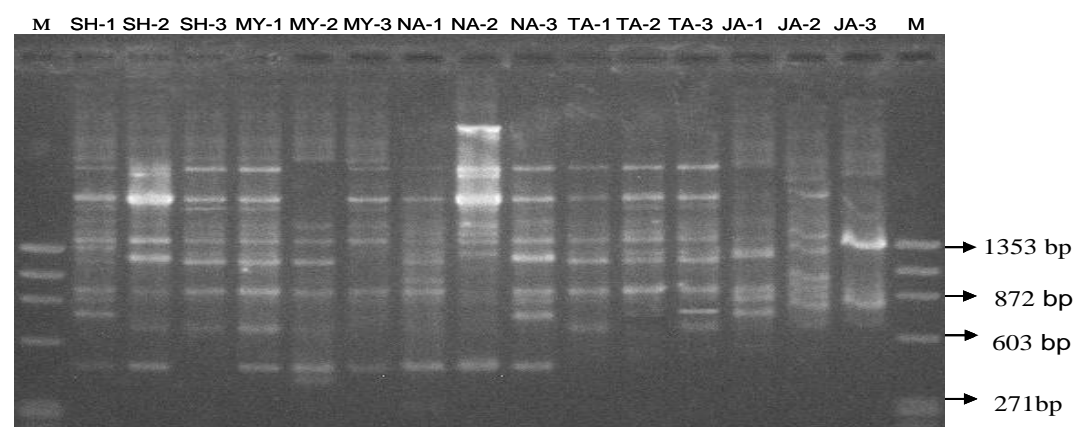

Fig.3. DNA Fingerprint profiles of 30 isolates of R.oryzae- sativae obtained with GF primer; (a) Isolates DE-1-NE-3 (b) Isolates SH-1-JA-3; Lanes: M, PhiX174/HaeIII markers (Promega).

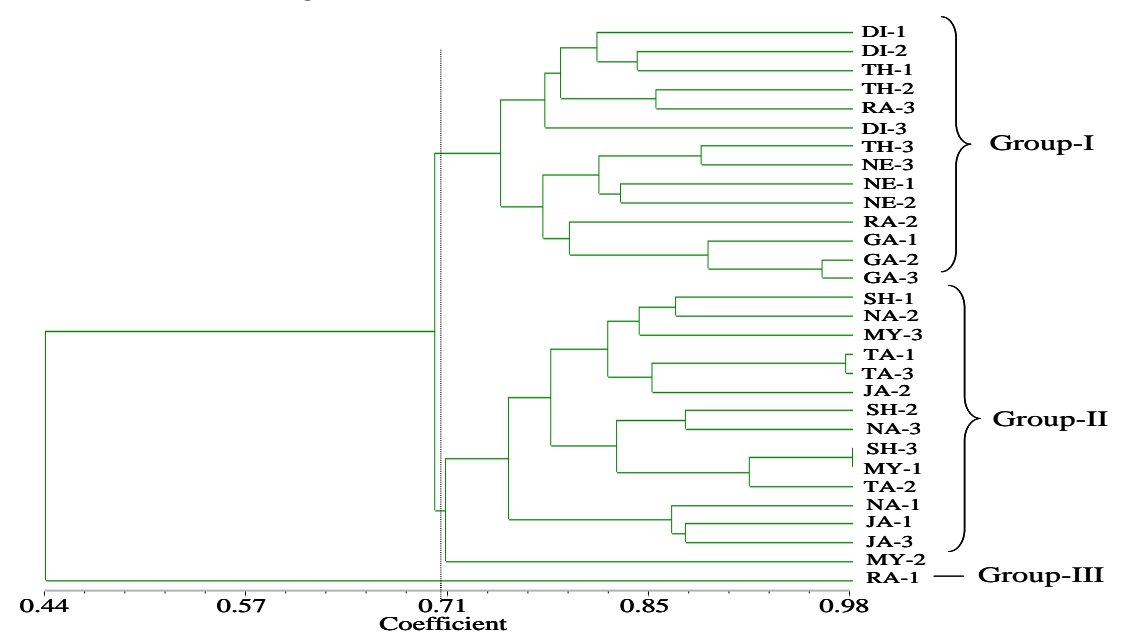

Fig.4. Dendrogram obtained from the combined data set of $30 \mathrm{R}$. oryzae-sativae isolates with VNTR and Rep-PCR markers 


\section{DISCUSSION}

In this study, the morphological qualitative characters like aerial mycelium colour of sclerotia and position of sclerotia (scattered, aggregated, on mycelia and on mycelia+embedded in agar) were found and consonant with (Chaijuckam et al., 2010 and Hossain et al., 2017). SCGs displayed high resolution by showing $90 \%$ diversity. Isolates with same multilocus genotypes were always in the same SCG (TA-1+TA-3) agreed with the findings of Chaijuckam et al. (2010). But in some isolates (MY$1+\mathrm{SH}-3$ ) with the almost same genotypes having same SCG were found in different rice field, meant that clones in populations were separated by up to $69 \mathrm{~km}$. Dissemination of asexual propagules is made possible by the transport of sclerotia or other asexual fungal structures in soil, flash flood, or by contaminated seeds over relatively long distance. In Texas, (Rosewich et al., 1999) identified isolates of Rhizoctonia solani in populations were separated by up to $280 \mathrm{~km}$ using an RFLP fingerprint probe.

The tested isolates of $R$. oryzae-sativae were classified genetically into three groups by using VNTR and rep-PCR primers at $69.6 \%$ similarity level. However, some relationship was observed between genetic variation and morphological characteristics, which clustered the isolates of Dinajpur, Thakurgaon, Rashahi, Gazipur and Netrakona in group I with low growth rate and some sclerotial categories. These results are in accordance with (Singh et al., 2002, Sharme et al., 2005 and Khodayari et al., 2009) reported that most of the microsclerotia forming isolates of $R$. solani were grouped together using RAPD and ISSR and ERIC primers. Group I isolates were from different agroecological zones. Low growth rate, small sclerotia and short RLH of group I isolates indicated a possibility of natural suppression on these isolates, and the influence of the environment on disease development might be a report for future epidemiological studies. The occurrence and distribution of rice sheath diseases is influenced by weather factors, physiological responses and agricultural practices (Datta, 1981). Nevertheless, further studies are required to provide a more extensive analysis of the existing population structure of the species at different areas in Bangladesh. The isolates did not cluster into according to their geographical origin. In addition, group I suggested also the possibility of gene flow of up to a distance of $378 \mathrm{~km}$ (maximum distance; GazipurThakurgaon), this is an agreement with the observations of found gene flow up to a distance of $716 \mathrm{~km}$ in Rhizoctonia solani by Rep-PCR fingerprinting (Aye et al.,2012). However, rest of the isolates clustered in group II (same AEZ, maximum distance Mymensingh-Narsingdi $135 \mathrm{~km}$.) with relatively fast growth rate, while isolate RA-1 collected from Rajshahi made a solitary cluster though having low growth rate and same sclerotial characteristics. RA-1 isolate exhibited null alleles in several primers, possibly caused by a mutation at the 3 end of the primer binding sites (Butler, 2005). 
Comparison of two molecular marker systems showed the highest number of scored DNA bands and a higher percentage of polymorphism were produced by the GF primer indicated VNTR was more efficient compared to that of Rep-PCR. Because, fingerprints generated by BOXA1R seemed to overlap adjacent bands (Versalovic et al., 1994). Though the primers and isolates used were relatively few in number, it could be effectively establish the molecular variability among the isolates of Bangladesh. However, at $90 \%$ similarity level, the isolates were categorized into 26 groups, which indicated a high genetic diversity of rice aggregate sheath spot fungus as revealed by VNTR and Rep-PCR primers. Variation in the isolates of $R$. oryzaesativae indicated that various genotypes of $R$. oryzae-sativae present in Bangladesh and should be included in screens of resistance genes in rice and fungicides.

\section{Conflict of interest}

There is no conflict of interest among the authors.

\section{Acknowledgements}

This work was done in Plant Pathology Division, Bangladesh Rice Research Institute, Gazipur-1701. First author sincerely acknowledge University Grant Commission, Bangladesh for financial support to perform the $\mathrm{PhD}$ research activities.

\section{REFERENCES}

Aye, S.S., and Matsumoto, M. (2012) Genetic Characterization by Rep-PCR of Myanmar Isolates of Rhizoctonia spp., Causal Agents of Rice Sheath Disease. Journal of Plant Pathology, 92(1), 255-260.

Barroso, G., Sonnenberg, A.S.M., Van Griensven, I.J.L.D., and Labarere, J. (2000) Molecular cloning of a widely distributed microsatellite core sequence from the cultivated mashroom Agaricus bisporus. Fungal Genetics Biology, 31, 115-123.

Butler, J.M. (2005) Forensic DNA typing: Biology, Technology and Genetics of SSR markers, Elsevier Academic Press, Burlington, MA.

Cedeno, L., Nass, H., Carrero, C., Cardona, R., Rodriguez, H., and Aleman, L. (1998) Rhizoctonia oryzae-sativae, agent of the aggregated stain of rice in Venezuela. Interciencia, 23, 248-251.

Chaijuckam, P., and Davis, R.M. (2010) Characterization of Diversity among isolates of $R$. oryzae-sativae from California Rice Fields. Plant disease, 94, 690-696.

Douhan, G.W. and Rizzo, D.M. (2003) Amplified fragment length microsatellites (AFLM) might be uesd to develop microsatellite markers in organisms with limited amounts of DNA applied to arbuscular mycorrhizal (AM) fungi. Mycologia, 95, 368-373.

Gunnel, P.S., and Webster, R.K. (1984). Aggregate sheath spot of rice in California, Plant disease. 68, 529-531.

Gunnel, P.S. (1992). Aggregate sheath spot. Pages 24-25 in: Compendium of rice disease. R. K. Webster and P. S. Gunnel, eds. American Phytopathological Society. St. Paul, MN. 
Guo, Q., Karmio. A., Sen sharma.B., Sagara, Y., Arakawa. M., and Inagaki, K. (2006). Survival and subsequent dispersal of rice sclerotial disease fungi, Rhizoctonia oryzae and Rhizoctonia oryzae-sativae, in paddy fields. Plant Disease. 90: 615-622.

Hossain. M, Sreenivasaprad, S., Meena. M., and Mia. M. A. (2017). A PCR Based analysis of genetic diversity of Rhizoctoniaoryzae-sativae in Bangladesh. International Journal of Agricultural Science and Natural Resource, 4(3) pp. 15-21.

Johanson A., Turner C.H., McKay J.G., and Brown E.A. (1998). A PCR-based method to distinguish fungi of the rice sheath-blight complex, Rhizoctonia solani, $R$. oryzae, $R$. oryzae-sativae. FEMS Microbiology Letters, 162 (1998) 289-294.

Khodayari M., Safaie N., and Shamsbakhsh, M. (2009). Genetic Diversity of Iranian AG11A isolates of Rhizoctonia solani, the Cause of Rice Sheath Blight, using Morphological and Molicular Markers. Journal of Phytopathol, 157: 708-714.

Kobayashi, T., Mew, T.W., and Hashiba, T. (1997). Relationship between incidences of rice sheath blight and primary inoculam in the philippines: Mycelia in plant debris and sclerotia. Annals of Phytopathological society of Japan, 63: 324-327.

Lanoiselet V.M., Cother E.J., and Ash G.J. (2007). Aggregate sheath spot and sheath spot of rice. Crop Protection 26: 799-808.

Mordue, J.E.M. (1974) Rhizoctonia oryzae-sativae. CMI (Commonw. Mycol. Inst. Descr. Pathology Fungi Bacteria, No. 409.

Raeder, U., and Broda, P. (1985). Rapid preparation of DNA from filamentous fungi. Letters of Applied Microbiology, 1: 17-20.

Rahimian, H. (1989). Occurrence of aggregate sheath spot of rice in Iran. Journal Phytopathology, 125: 41-46.

Rosewich, U.l., Pettway R.E., McDonald, B.A., and Kistler H.C. (1999). High level of gene flow and heterozygote excess characterize Rhizoctonia solani AG-1 IA (Thanatephorus cucumeris), from Texas. Fungul Genetics Biology, 28: 148-159.

Singh V., Singh U.S., Singh K.P., Singh M., and Kumar A. (2002). Genetic Diversity of Rhizoctonia solani isolated from rice: differentiation by morphological characteristics, pathogenicity, anastomosis behaviour and RAPD fingerprinting. Jounal Mycology Plant Pathology, 2: 332-344.

Sharma M., Gupta S.K., and Sharma T.R. (2005). Characterization of variability in Rhizoctonia solani by using morphological and molicular markers. Phytopathology, 153: 449-456.

Sneh, B., Burpee, I., and Ogoshi, A. (1991). Identification of Rhizoctonia Species. American Phytopathological Society. St. Paul, MN.

Taheri, P., Gnanamanickam, S., and Hofte, M. (2007). Characterization, Genetic Structure and Pathogenicity of Rhizoctonia spp. Associated with Roce Sheath diseases in India. Phytopathology, 97: 373-783.

Versalovic, J., Schneider, M., de Bruijn, F. J., and Lupski, J. R. (1994). Genomic fingerprint of bacteria using repetitive sequence-based polymerase chain reaction. Methods in Molecular and Cell Biology, 5:25-40.

Vandermark, G. J. (1999). Detection of polymorphisms in fungi using the AFLP technique and agarose gels. Focus, 21: 26. 